\title{
On Problems of College Campus Dance Creation
}

\author{
Yingping Zhu \\ Music and Dance College \\ Zhongzhou University \\ Zhengzhou, Henan 450044.China \\ Zhuyingping3168@163.com
}

\begin{abstract}
To fully implement Chinese education policy and promote college students' comprehensive development, the Ministry of Education holds the national college students' art performance activities once every three years, in order to exhibit the achievement of art education of higher institutions. In all previous national level (province) of college students' art performance activities, a batch of excellent works of dance have emerged, but at the same time some problems also appear. For example, limited campus creative subjects, cliched dance themes, unclear dance theme, lack of logic in dance structure, and so on. According to the Ministry of Education requirements of the college students' art performance activities and problems in the performance of dance, we put forward some suggestions to solve the key problems in campus dance creation.

Dance education has become an important part of aesthetic education in higher schools, and acted as a display of school art education achievement and one of the important ways of campus culture. This is decided by high attachment to art education in colleges and universities by Ministry of Education and characteristics of dance art. Since the first college students' art performance activities in 2005 to the third national college students' art performance activities in 2012, the college students dance performance works has been transformed from imitation to creation, among which national dance accounted for more than $60 \%$, all kinds of subjects of modern dance, classical dance accounted for $30 \%$, and works reflecting the campus dance less than $10 \%$. So on the dance symposium after college students' art performance ach year, dancer judges and the general dance teachers give their sigh for it. According to the survey, many colleges and universities dance teachers are racking their minds to create campus dance, but ultimately they fail to enter the finals. The main reason is that they fail to seize the key points of the college campus dance creation.
\end{abstract}

Key words: college students; campus dance; theme; structure; method

\section{THE THEME OF CAMPUS DANCE CREATION}

Dance creation is like writing an article, which must have a conception--- theme, namely "What shall we make up?" As college campus dance creation, first of all, we must make sure that the body of the object is college student; Second, the creative conception should be established according to the theme of each activity. Such as, the theme of the second national university art performance activities is "motherland and I". So our dance creation should focus on "contemporary college students love the motherland, socialism and their optimistic and cheerful, positive spirit. We should express college students' great aspiration and historical sense of mission to realize the great rejuvenation of the Chinese nation. The dance shows the elegant and healthy aesthetic pursuit of college students"(1). Another case, the third session of the theme of the college students' art performance activities was "youth \& mission". Therefore, we should stick to dance creation activity theme. Thirdly, we should pay attention to the special requirements of each "national activities (such as guiding ideology, content). For example, the guiding ideology of the third national college students' art performance activities is "insisting on education, with the orientation of advanced culture; carrying forward the great spirit of the Chinese nation, reflecting the socialist core values, showing the contemporary university students' striving spirit; facing all the college students, based on improving aesthetic accomplishment and humane quality, promoting the all-round development of morality, intelligence and physique; exhibiting fruitful results of high school art education, creating healthy and elegant campus culture atmosphere, reflecting real, good, elegant, upward campus cultural characteristics"(2); In its content, it stressed "Activities should achieve the unification of the thoughts and artistry, being innovative, and reflect the era characteristic, the campus feature and characteristics of students "(3). Therefore, in the beginning of our dance creation, our theme should meet the above three requirements. For example, the rewarded dance "Chinese Boys' Remark" and "Two Hands of the Earth" in The Second National University Art Performance have left a deep impression on the audience. The rewarding reason is that these art works have good and attractive themes. In addition, some themes of dance works are based on students' campus life, such as "Wearing academic dress", "Village official election", "Job waltz" and so on. These dance works either capture the students' emotion to their alma mater, or directly reflect the real life of college students, so they have the characteristics of modern age and are very moving. Another rewarded dance work "The dancing sun" combines street dance, jazz elements and campus life, the student extracurricular activity materials together. The famous dancer professor Zhi tao Pan once said in the dance symposium of the second national university art show: "In the past national university art show, street dance never entered into finals. We don't forbid our students jump street dance, but the key is what the content of their dance performance is? Is it sunshine, upward, and vibrant campus life, or generally funny city folk or imitation of foreign street dance"(4). Therefore, in dance creation, we should stick to the theme, which is the life to the dance. 


\section{THE STRUCTURE OF DANCE CREATION}

The structure (framework) of dance is very important, for dance creation is logical. A good dance is just like a good article, which has proper theme and structure. That is how to make up the dance. Dance art is a kind of dynamic work of art. Therefore, guided by the logical thought, the creation of dance choreography is to build "structure" and make dance language combination after careful design. No matter what kinds of dance works creation are, "structure" is the first problem to face and solve. When a choreographer ascertains the theme of a dance work, he will construct out a mental predisposition "rendering" from his aesthetic and creative experience according to team member's conditions, comprehensive qualities, in which he decides the dance of the whole and the paragraph arrangement, performance style, dance language tone, gold dividing point, music, costumes and props. At the same time, a choreographer should design self-expressing dance emotional logic development in the theme by his own feeling to the work. He should conceive the logical blueprint---dance "frame" of the future dance in which, every step is linked together, and with reasonable pushing up. So in the later stage of creation, the choreographer will achieve the idea through the choreography of dance vocabulary. This process of "design" is the director's "structure" process. Structure is a kind of technique, and structure process must make service for the ideas what one wants to express. A good dance includes creative idea + logic structure + proper technique. So, on the basis of innovation conception, a logical structure scheme is also very critical.

\section{EXPRESSING TECHNIQUE OF CAMPUS DANCE}

\section{CREATION}

First, we should make clear that the dance techniques how to make service for the dance theme, correctly handle the relationship between the form and content. Campus dance creation should avoid the pursuit and display of skills. The choreographer should think about, express and solve this problem standing on the perspective of era characteristics, school characteristics, and characteristics of students. Campus dance should to express campus, student typical and profound life experience, reflect students' youthful, sunshine, active campus cultural characteristics by beautiful body language. It should avoid only paying attention to the skills. Professor Yue Ma said: "It is meaningless and worthless to have good form without a good theme (nonpolitical content). Good work should be good content plus good form..." (5) Professor Zhitao Pan once talked about dance skills: "The dance work should express a word "alive". The skills are tool. If we only pursue skill itself, the dance would die." (6) For example, the rewarded "Sunny Suoma" in the second college art show left deep impression on the audience. The dancing skill is very simple, as simple as just a group of boys and girls dancing in Tibetan costumes. From beginning to end, there is no complex team formation change, no skill of difficult movements. Yet, they jump the dance with happiness, passion, youth and sunshine. All the audiences are moved by their smile and cheerful passionate dance. Professor Zhitao Pan said: "The purpose of college students' art show is to let more students to attend the art activities. We hope the students can dance happily, healthy, and make full self-expression. This is what our director really pursues in the dance creation". (7)

Secondly, the language and words of dance should be caught and refined in the theme, era feature, and ethic style. The dance movement is the direct reflection of idea and emotion, and it is the main element in dance creation. So when a choreographer creates a dance, the use of any dance movement and words, should be closely around the theme, era characteristics, national style. He not only had to refine, process and combine dance movement materials stored in the brain, but also he had to rhythm and picture the typical and profound and dynamic experience in daily life, so as to achieve the best state of dance emotion, dance idea and dance language. For example, in the rewarded dance "Double hands" in the second college student art show, with "May $12^{\text {th }}$ earthquake" as the background of this dance, the choreographer designed a theme of action of two hands harrowing the ground to move bricks. This action went throughout the dance over and over. The dance language is concise, refined, profound, focused and clear. Similarly, in the dance "Chinese mother", the choreographer used non-exaggerate and emotional expression and action to show completely a series of complicated psychological change process of hatred, acceptance, parenting, seeing off. There is not difficult or flashy moving skill. However, this dance was awarded the golden prize in the $7^{\text {th }}$ national dance competition, became the popular and welcome dance in the second college students art performance show.

Thirdly, dance language should be simple, refined, smooth, clear hierarchy. For example, in the rewarded dance "jasmine" in the second national university art performance, there is no difficult dance movement in it. What it has is southern beauty's gentle flowing dance movements. What we saw is "green", "water", "gentle", and "beautiful". The dance, dance beauty and music impressed audience with a kind of pure and fresh quietly elegant southern life scenery.

Fourth, we should pay attention to the consistency of dance music, dance theme, paragraphs and the expression skill. Music is the soul of dance, and dance is the carrier of music. We can play music without dance, but we can not perform dance without music. Dance is the art of time and space, namely, it is audio and visual art. Therefore, the choreographer should pay attention to the consistency between dance theme, style, tone structure, rhyme, climax (golden section ratio) with dance theme movements, logic structure, dance emotion, dance idea, dance language expression. We should avoid scraping together dance music. For example, the spin in the dance should be finished by the support of music's rhythm, repetition, superposition of sound. The base of dance is the 
rhythm, which is the skeleton of the dance. At the same time, rhyme is a chain which links various movements and forms regular, ups and downs action combination. The common used skills in dance creation by dancer Jigang Zhang are rhythm, repetition, superposition and spin. The simple repetition is a kind of force. The spin is the repetition and superposition in different time and space. Therefore, a powerful, infective dance works must be supported by powerful infective music. Without the support of music, the climax of music does not exist.

Fifth point, the dance should be consistent with stage artistic design. Namely, the dance should be consistent with stage lighting design, ethnic style clothing, props, and makeup. They should match with each other exactly. Blindly chasing after fashion is useless and meaningless. For example, a Tibetan-style dance works "Wind of Tanggula" from one college in the second college art show is quite good in the design and performance. But there is something wrong with costume. The costume of the Tibetan clothing is usually covering right shoulder and exposing left shoulder in its coat, but the flesh of left should is covered. However, the costume of this dance is on the opposite side with left shoulder naked. Ultimately it didn't get good achievement. Another example, the dance works "Chinese mother" in this art show is staged many times. Mother's costume of one team adopted smooth silk material. When the dancers wear the costume, they look like evil rich landlady which twisted the image of Chinese mother in the Sino-Japanese war. Professor Zhitao Pan comments that "A dance can show cognitive level of beauty of a school leaders and teachers. It reflects not only the quality of an art work, at the same time it embodies a school's art education level and the cultural connotation "(8).

\section{CONCLUSION}

College campus dance creation should closely connect with era characteristics, school characteristics, characteristics of students, promotion of the national culture spirit. Dance choreography and form are important, but the theme and conception design of a dance is more important. The purpose of the national college students' art show held by the Ministry of Education, aims to improve students' aesthetic accomplishment and humane accomplishment, present college students' healthy and upward spirit, promoting student all-round development of morality, intelligence and physique. Therefore, skill has value in the true sense when it serves for the noble theme.

\section{ANNOTATION}

(1)“'On the Second National University Art Performance

Activities"[EB/OL].( 2007-09-27)[2007-10-13]http://w ww.csmes.org

(2)/(3) The Ministry of Education: "On the Third National University Art Performance Activities"[EB/OL].( 2010-09-15)[2010-10-11]http://w ww.csmes.org

$(4) /(5) /(6) /(7) /(8)$ Dance Symposium of the second national university art performance, Nanjing, 2009.

\section{REFERENCES}

[1] Yisheng Lu. Introduction on Dance Learning [M]. Shanghai: Shanghai Music Publishing House, 2003.

[2] Yinpei Long, Erchong Xu. Introduction on Dance Art [M]. Shanghai: Shanghai Music Publishing House, 1997.

[3] Shufang Han, Shumei Han. Structure Is Function--- Structure Creation, in Dance Creation. [J]. Journal of Qinghai Nationalities Research, 2008. 